\section{ZEW}

Zentrum für Europäische Wirtschaftsforschung GmbH

Centre for European Economic Research

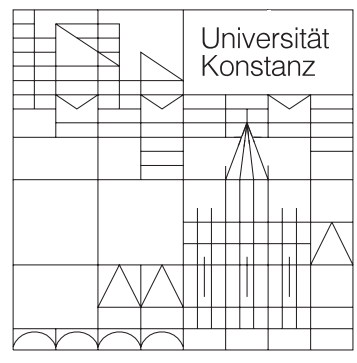

Rechts-, Wirtschafts- und Verwaltungswissenschaftliche Sektion Fachbereich

Wirtschaftswissenschaften

Diskussionspapiere der DFG-

Forschergruppe (Nr.: 3468269275):

Heterogene Arbeit: Positive und Normative Aspekte der Qualifikationsstruktur der Arbeit

Florian Baumann

Nikolai Stähler

Financing Unemployment Benefits: Dismissal versus Employment Taxes

Februar 2005 
Diskussionspapier der Forschergruppe (Nr.: 3468269275) "Heterogene Arbeit: Positive und Normative Aspekte der Qualifikationsstruktur der Arbeit"

Nr. 05/03, Februar 2005

\section{Financing Unemployment Benefits: Dismissal versus Employment Taxes}

\section{Florian Baumann}

\author{
Johannes-Gutenberg-Universität Mainz \\ Abteilung Wirtschaftswissenschaften \\ FB03/LS Goerke \\ Jakob-Welder-Weg 4 \\ 55128 Mainz
}

$$
\begin{aligned}
& \text { mail : florian.baumann@uni-mainz.de } \\
& \text { phone : } \\
& \text { fax }: \text { +49-6131-39-23228 }
\end{aligned}
$$

\author{
Nikolai Stähler \\ Johannes-Gutenberg-Universität Mainz \\ Abteilung Wirtschaftswissenschaften \\ FB03/LS Goerke \\ Jakob-Welder-Weg 5 \\ 55128 Mainz \\ mail : staehl@uni-mainz.de \\ phone : +49-6131-39-25442 \\ fax : $+49-6131-39-23827$
}

\section{Zusammenfassung:}

This paper investigates the effects of using dismissal taxes to finance unemployment benefits. We compare dismissal and employment taxes in a model with search frictions. Employment taxes give rise to externalities because firms do not take into account the effects their dismissal decisions have on others. By introducing dismissal taxes to finance unemployment insurance, these externalities can partly be internalized. Taking into account the budget of the unemployment insurance, employment taxes can be reduced by more than necessary to offset the adverse effect of dismissal taxes on the firm value. The introduction of dismissal taxes leads to higher job creation and lower unemployment, in contrast to standard results concerning employment protection.

\footnotetext{
JEL Klassifikation

: J41, J64, J65, J68

Schlüsselwörter

employment protection, search and matching models, unemployment, unemployment insurance 


\title{
Financing Unemployment Benefits: Dismissal versus Employment Taxes
}

\author{
Florian Baumann and Nikolai Stähler * \\ University of Mainz
}

January 20, 2005

\begin{abstract}
This paper investigates the effects of using dismissal taxes to finance unemployment benefits. We compare dismissal and employment taxes in a model with search frictions. Employment taxes give rise to externalities because firms do not take into account the effects their dismissal decisions have on others. These externalities can be tackled by using dismissal taxes to finance unemployment insurance. Taking into account the budget of the unemployment insurance, employment taxes can be reduced by more than is necessary to offset the adverse effect of dismissal taxes on the firm value. The introduction of dismissal taxes leads to higher job creation and lower unemployment, in contrast to standard results concerning employment protection.
\end{abstract}

Theme: Labour Market Policy

Keywords: employment protection, search and matching models, unemployment, unemployment insurance

JEL-Code: J 41, J 64, J 65, J 68

*Address correspondence to: Nikolai Stähler, University of Mainz, Department of Economics (FB03/LS Goerke), Jakob-Welder-Weg 5, 55099 Mainz, Germany. Email: staehl@uni-mainz.de.

We would like to thank Tim Friehe, Laszlo Goerke, Magnus Hoffmann, and Martin Kolmar for patiently answering our questions concerning the consistency of the model. 


\section{Introduction}

Among politicians and economists, employment protection is assumed to be one of the causes for high unemployment rates. It has been argued that especially re-employment possibilities for unemployed workers are reduced (OECD 2004).

Theoretically a clear link between employment protection and high unemployment rates has not been found. Employment protection has mainly been modeled by some kind of dismissal costs (taxes), which are paid to some third party. They reduce dismissals but at the same time reduce job creation and therefore the effect on the unemployment rate is ambiguous (see, for example, Bertola 1990, 1999, Garibaldi 1998, Mortensen and Pissarides 2001).

Lately the interaction between employment protection and other labor market institutions, namely unemployment insurance, has come to the fore. Dismissals represent social costs, which the causer of these costs, notably the employer, is not made responsible for. Properly designed employment protection rules deal with this problem, but it is claimed that the negative effect on job creation when increasing employment protection still remains (OECD 2004). We show that by changing the financing system of unemployment benefits by substituting employment taxes by dismissal taxes, job creation can indeed be increased while unemployment can be reduced ${ }^{1}$.

Financing unemployment benefits through employment taxes leads to externalities in the way that firms which are firing workers and hence create additional costs to the unemployment insurance are not made responsible for this action. To internalize these externalities, firms can be made liable for their behavior by changing the financing system toward a system with dismissal taxes that firms have to pay when firing a worker. The proceeds are used to lower employment taxes. Such a financing system can be interpreted as unemployment insurance with experience rating (see Mortensen, Pissarides 1999). In the USA, such a system with experience rating exists (see for example Anderson, Meyer 2000). For Germany, a proposal for such a change in financing can be found in the 2003 annual report of the German Council of Economic Experts.

Using a matching model with a two-tier wage contract in line with Mortensen and Pissarides $(1994,1999,2001)$, augmented by the budget constraint of the unemployment insurance, we investigate how such a financing change influences the dismissal and job creation behavior of firms and what consequences result for the unemployment rate in the economy ${ }^{2}$.

\footnotetext{
${ }^{1}$ Referring to Belot et al. (2002), the OECD report states that if employment protection gives incentives for workers to invest in firm-specific human capital, "the resulting productivity gains could compensate for the depressive effect that firing costs may have on job creation" (OECD 2004, p. 91). We show that this incentive is not necessary for our results to hold.

${ }^{2}$ The paper does not address the question which level of unemployment benefits should be paid for efficiency reasons. We take unemployment benefits as given since they exist in nearly every developed country. A theoretical explanation could be to assume that individuals will need the minimum amount of unemployment benefits to survive (and therefore have a corresponding utility function). This argumentation is in line with Bovenberg (2003).
} 
In line with former literature, dismissal taxes by themselves still cause ambiguous effects on the unemployment rate. But using the proceeds of dismissal taxes to finance the unemployment insurance, we show that the negative effect on job creation is reversed and unemployment can be reduced.

By using dismissal taxes the externality that individual employment policies affect other firms is taken into account. Concerning the layoff decision firms and workers only take into consideration their personal profits. Due to dismissal taxes, the social costs of layoffs - a rise in unemployment insurance contributions - are internalized. We find that therefore employment taxes can be reduced by more than necessary to offset the negative effect of dismissal taxes on the firm value. Job creation increases. Our results relate to Blanchard and Tirole (2004), who, using a different model framework, reach similar conclusions concerning the optimal design of financing unemployment insurance. To our knowledge, solving matching models with an integrated budget constraint for the unemployment insurance has mainly been done by a simulation approach so far (see Millard and Mortensen 1997 for example).

With this kind of modeling we show that employment protection does not necessarily deteriorate re-employment possibilities for the unemployed. More employment protection can indeed reduce unemployment.

We will proceed as follows. Section 2 describes the basic structure of the model. Section 3 deals with the effects of a change in the financing of unemployment insurance. We relate the results to the literature and point out the differences of our model. In section 4, the main findings are summarized. Additionally, a mathematical appendix is added.

\section{The Model}

We consider an economy in continuous time. Population is normalized to one. The labor market is characterized by search frictions. Unemployment $u$ and vacant jobs $v$ exist at the same time. Open positions are filled when an unemployed matches with a vacancy. This process is described by a linear homogeneous and concave matching function $m(u, v)$. The number of vacancies and therefore market tightness $\theta=v / u$ is determined endogenously and determines the process of job creation. The rate at which vacant jobs are filled is given by $q(\theta)=\frac{m(u, v)}{v}=m(1 / \theta, 1)$ where $q^{\prime}(\theta)<0$. Unemployed find a new job at rate $\theta q(\theta)=\frac{m(u, v)}{u}$ where $(\theta q(\theta))^{\prime}>0$.

Because of the search frictions, economic rents accrue to a matched firm-worker pair. The sharing rule for these rents is determined by Nash-bargaining over wages between firms and workers.

The productivity of existing jobs depends on idiosyncratic productivity shocks. Firmworker matches will be dissolved when the productivity of the job falls short of some threshold productivity level. This reservation productivity, governing the process of job destruction, is also determined endogenously.

The government maintains mandatory unemployment insurance. Each unemployed ob- 
tains benefits $b$ per period. To finance these benefits, the government can rely on contributions per employed $t$ (modeled as an employment tax) or dismissal taxes $T$ that have to be paid by firms when laying off a worker.

In what follows, the mathematical structure of the model will be described in more detail in line with Pissarides (2000) and Mortensen and Pissarides (2001). First, we characterize firm and worker behavior according to the respective Bellman equations. After describing the process of wage determination, two central equations which govern job creation (according to market tightness) and job destruction (according to the reservation productivity) are derived for given policy parameters. For given unemployment compensation, the government has to select its policy parameters (employment and dismissal taxes) to balance the budget of the unemployment insurance.

\section{Firms}

Each firm has one position to offer which can be either filled (job) or vacant (vacancy). The idiosyncratic productivity of a filled job $\epsilon \in\left[\epsilon_{l}, \epsilon_{u}\right]$ is distributed according to the cumulative distribution function $G(\epsilon)$, with $g(\epsilon)$ being the corresponding density function. Shocks occur to every single job at the Poisson rate $\lambda$. In case of a shock, a new idiosyncratic productivity is drawn from the distribution $G(\epsilon)$. The value of the firm $J(\epsilon)$ depends on current profits and the option value of a possible shock. Current profits are given by the difference between productivity and gross wages. The latter equals net wages $w(\epsilon)$ and the employment tax $t$. If productivity falls below the endogenous reservation productivity $\epsilon_{d}$, the job will be destroyed, in which case the firm has to pay the dismissal tax $T$. With $r$ being the interest rate in the economy the Bellman equation for continuing firms reads

$$
r J(\epsilon)=\epsilon-w(\epsilon)-t+\lambda\left[\int_{\epsilon_{d}}^{\epsilon_{u}} J(x) d G(x)+G\left(\epsilon_{d}\right)(-T)-J(\epsilon)\right] .
$$

Newly created jobs are endowed with the highest possible productivity $\epsilon_{u}{ }^{3}$. Given an initial wage $w^{0}$, the Bellman equation for a new job satisfies

$$
r J^{0}=\epsilon_{u}-w^{0}-t+\lambda\left[\int_{\epsilon_{d}}^{\epsilon_{u}} J(x) d G(x)+G\left(\epsilon_{d}\right)(-T)-J^{0}\right] .
$$

Analogously, we derive the Bellman equation for a vacancy $V$. Recruitment costs are given by $c$ per period.

$$
r V=-c+q(\theta)\left[J^{0}-V\right]
$$

Free entry for firms implies that vacancies will be created as long as their present value is greater than zero. Accordingly, in equilibrium $V=0$ has to hold, yielding

$$
J^{0}=\frac{c}{q(\theta)} .
$$

\footnotetext{
${ }^{3}$ We assume that firms choose the best current technology when creating a new job. See also Pissarides (2000).
} 
Equation (4) implies that the present value of a newly created job has to equal the search $\operatorname{costs} c$ per period times the average search duration $1 / q(\theta)$.

\section{Workers}

Workers can either be employed (with lifetime utility $W(\epsilon)$ in continuing jobs or utility $W^{0}$ in a new job) or unemployed (with utility $U$ ). If unemployed, they receive unemployment benefits $b$. Given the probability of finding a new job, the corresponding Bellman equation for the unemployed satisfies

$$
r U=b+\theta q(\theta)\left(W^{0}-U\right) .
$$

Employed workers earn net wages $w(\epsilon)$ in continuing and $w^{0}$ in new jobs. If the productivity of the job falls below the reservation productivity $\epsilon_{d}$, the worker becomes unemployed. Similar to the description of firms, the Bellman equations depicting a worker's payoffs read

$$
\begin{gathered}
r W(\epsilon)=w(\epsilon)+\lambda\left[\int_{\epsilon_{d}}^{\epsilon_{u}} W(x) d G(x)+G\left(\epsilon_{d}\right) U-W(\epsilon)\right], \\
r W^{0}=w^{0}+\lambda\left[\int_{\epsilon_{d}}^{\epsilon_{u}} W(x) d G(x)+G\left(\epsilon_{d}\right) U-W^{0}\right] .
\end{gathered}
$$

\section{Wage determination}

Wage bargaining is modeled as a Nash-bargaining procedure between the worker and the firm where $\beta$ mirrors the bargaining power of the worker. Wages are renegotiated in case a shock occurs. In continuing jobs, the fall-back position for the firm is given by the payment $T$, which has to be made in case of a layoff, while the threat point of workers is given by the utility of an unemployed $U$. In contrast, if employer and employee bargain over the initial wage before a contract is made, the fall back position of the employer is given by the value of a vacancy, which equals zero in equilibrium. Therefore, we get a two-tier wage contract supporting

$$
\begin{gathered}
w(\epsilon)=\arg \max (W(\epsilon)-U)^{\beta}(J(\epsilon)+T)^{1-\beta}, \\
w^{0}=\arg \max \left(W^{0}-U\right)^{\beta} J^{0^{1-\beta}} .
\end{gathered}
$$

The maximization problems of equations (8) and (9) imply the sharing rules (for calculations see Appendix A)

$$
\begin{gathered}
\beta(J(\epsilon)+T)=(1-\beta)(W(\epsilon)-U), \\
\beta J^{0}=(1-\beta)\left(W^{0}-U\right) .
\end{gathered}
$$

The resulting wages are

$$
\begin{gathered}
w(\epsilon)=\beta(\epsilon-t+r T+\theta c)+(1-\beta) b \\
w^{0}=\beta\left(\epsilon_{u}-t-\lambda T+\theta c\right)+(1-\beta) b=w\left(\epsilon_{u}\right)-\beta(r+\lambda) T .
\end{gathered}
$$


Wages decrease with employment taxes $t$ as, from the perspective of the firm-worker pair, they are equivalent to a decrease in the productivity of the job. Considering dismissal taxes $T$, workers in continuing jobs can earn higher wages. But since the increase in wages is foreseen by firms and workers, and dismissal taxes decrease the expected surplus of the match, initial wages decrease with dismissal taxes. The initial lower wage acts like a bond, paid by workers, which compensates the firm for the higher wages in continuing jobs. The two-tier wage structure guarantees that workers share dismissal taxes as employment taxes according to their bargaining power (see Mortensen and Pissarides 2001).

\section{Job destruction and job creation}

For given policy parameters, the market equilibrium is specified by the two endogenous variables market tightness $\theta$ and reservation productivity $\epsilon_{d}$, governing the processes of job creation and job destruction. The reservation productivity is determined by the job destruction condition that the worker will be dismissed, if the firm value falls below the negative dismissal tax. Therefore,

$$
J\left(\epsilon_{d}\right)=-T
$$

Equation (14) in combination with equation (10) implies that job destruction is privately efficient from the viewpoint of the firm-worker pair. The lifetime utility of employment equals the lifetime utility of unemployment at the reservation productivity. But as the two parties do not take into consideration the impact of their decision on the unemployment insurance, an externality arises as long as employment taxes are positive $(t>0)$. After closing the job the financial need of the insurance is increasing while at the same time no more employment taxes are paid by this specific firm-worker pair.

As stated earlier, market tightness $\theta$ is determined by free market entry for firms, equation (4). Substituting the wage equations (12) and (13) into the Bellman equations (1) and (2), and using equations (14) and (4), we derive (for calculations see Appendix B)

$$
\epsilon_{d}-t+\frac{\lambda}{r+\lambda} \int_{\epsilon_{d}}^{\epsilon_{u}}\left(z-\epsilon_{d}\right) d G(z)=b+\frac{\beta}{1-\beta} c \theta-r T
$$

as job destruction condition (JD) and

$$
\frac{(1-\beta)\left(\epsilon_{u}-\epsilon_{d}\right)}{r+\lambda}-(1-\beta) T=\frac{c}{q(\theta)}
$$

as job creation condition (JC).

Equations (15) and (16) jointly determine the equilibrium values of the reservation productivity $\epsilon_{d}$ and market tightness $\theta$. The JD implies a positive relationship between reservation productivity and market tightness since wages increase with market tightness. Therefore existing jobs are dissolved at higher productivity levels. The JC implies a negative relationship between market tightness and reservation productivity since a higher reservation productivity goes along with a shorter expected lifetime of the job and therefore firm 
value decreases. This must be offset by lower recruitment cost, that is a shorter expected time of search and therefore lower market tightness. The influence of the policy parameters on JD and JC will be described in detail in section 3.

\section{Unemployment}

Unemployment is determined by inflows $\left(\lambda G\left(\epsilon_{d}\right)(1-u)\right)$ and outflows $(\theta q(\theta) u)$ according to the job destruction and job creation decisions of firms. In steady state the change in unemployment is zero and the unemployment rate is given by

$$
u=\frac{\lambda G\left(\epsilon_{d}\right)}{\lambda G\left(\epsilon_{d}\right)+\theta q(\theta)} .
$$

\section{Government}

The state has to finance expenditure for unemployment insurance, bu. The government obtains income from employment taxes $t$ per employed and from dismissal taxes $T$ for each worker fired. Therefore, the government's budget constraint reads

$$
b u=t(1-u)+T \lambda G\left(\epsilon_{d}\right)(1-u) .
$$

\section{Equilibrium}

The equilibrium of the economy is determined by the policy parameters $t$ and $T$ and the corresponding equilibrium values of market tightness $\theta$ and reservation productivity $\epsilon_{d}$. The latter two determine the steady state unemployment rate $u$. The policy parameters are chosen in such a way that the governments budget is balanced in steady state. Therefore, the corresponding equilibrium values are obtained by simultaneously solving equations (15), (16), (17) and (18) for pre-determined $t$ or $T^{4}$.

\section{Comparative Statics}

The following analysis deals with the question of what will happen if the system of financing unemployment benefits will be changed to a system where dismissal taxes play a more important role. We restrict our attention to the steady state. Using equations (15) and (16), we first describe the basic effects when introducing dismissal taxes, neglecting the budget

\footnotetext{
${ }^{4}$ For given dismissal taxes, there may exist multiple equilibria. For example, there could exist an equilibrium with high employment taxes and high unemployment as well as an equilibrium with low employment taxes and low unemployment. According to Rocheteau (1999a and 1999b), the government can guarantee the lower unemployment rate by setting the policy parameters $t$ and $T$ and adjusting unemployment benefits until the economy reaches the low unemployment equilibrium.
} 
constraint, to relate to the findings of the former literature on employment protection. In a second step, we introduce the effects of the budget constraint by using equations (17) and (18) and illuminate the results. We find that under certain conditions, the negative effect of dismissal taxes on job creation is reversed. Therefore, unemployment unambiguously decreases when substituting employment taxes by dismissal taxes.

Differentiating the JD, equation (15), yields

$$
-\frac{1}{r+\lambda}\left(r+\lambda G\left(\epsilon_{d}\right)\right) d \epsilon_{d}+\frac{\beta c}{1-\beta} d \theta=r d T-d t .
$$

The reservation productivity falls with dismissal taxes $T$ as it becomes more expensive to dismiss an employee. It increases with employment taxes $t$, since from the point of view of the job-worker-pair, net productivity is decreased.

For the JC, equation (16), we obtain

$$
-\frac{1-\beta}{r+\lambda} d \epsilon_{d}-(1-\beta) d T=-\frac{c}{q(\theta)^{2}} q^{\prime}(\theta) d \theta .
$$

Equation (20) states that the change in the expected value of a new job equals the change in search costs. The reservation productivity is chosen optimally by the firm according to JD. To get a better understanding of the effects at work, solving equation (19) for the change in the reservation productivity $d \epsilon_{d}$ and inserting the result into equation (20), the change in the value of a new job is given by

$$
d J^{0}=-\frac{1-\beta}{r+\lambda G\left(\epsilon_{d}\right)}\left[d t+\lambda G\left(\epsilon_{d}\right) d T\right]-\frac{\beta c}{r+\lambda G\left(\epsilon_{d}\right)} d \theta .
$$

As the rate at which jobs are destroyed is given by $\lambda G\left(\epsilon_{d}\right)$, the adjusted discount factor for the firm equals $r+\lambda G\left(\epsilon_{d}\right)$. The firm bears part $(1-\beta)$ of an increase in employment taxes $t$ or expected dismissal cost $\lambda G\left(\epsilon_{d}\right) T$ per period. An increase in market tightness $\theta$ improves the outside option of workers and thereby wages. The latter fact is described by the last term on the rhs of equation (21).

Neglecting the budget constraint, equations (19) and (20) can be solved simultaneously to calculate the effects on reservation productivity and market tightness due to changes in the policy parameters $t$ and $T$ (for calculations see Appendix $\mathrm{C}$ ).

$$
d \epsilon_{d}=-\frac{1}{D} \frac{c}{q(\theta)^{2}} q^{\prime}(\theta) d t+\frac{1}{D}\left(\frac{r c}{q(\theta)^{2}} q^{\prime}(\theta)-\beta c\right) d T
$$

and

$$
d \theta=-\frac{1}{D} \frac{(1-\beta)}{r+\lambda} d t-\frac{1}{D} \frac{(1-\beta)}{r+\lambda} \lambda G\left(\epsilon_{d}\right) d T
$$

where

$$
D=-\frac{1}{r+\lambda}\left(r+\lambda G\left(\epsilon_{d}\right)\right) \frac{c}{q(\theta)^{2}} q^{\prime}(\theta)+\frac{\beta c}{r+\lambda}>0 .
$$


An increase in employment taxes $t$ leads to an increase in the reservation productivity and a fall in market tightness. Rising employment taxes reduces the net productivity of a given job. This means that the productivity necessary to hold the job active has to increase. At the same time, firm value decreases and therefore fewer vacancies are offered. An increase in dismissal taxes $T$ lowers the reservation productivity. Market tightness decreases as well. Rising dismissal taxes directly influence the reservation threshold for an existing job by changing the opportunity outcome for the firm if the employment relationship is dissolved. Therefore more jobs are held active, but because the firm value falls, fewer jobs are created. These findings correspond to the literature, pointing out that employment protection will lead to less dismissals but at the same time diminish the incentives for creating new jobs ${ }^{5}$. For a rise in dismissal taxes, the effect on the unemployment rate is ambiguous because the effects on the reservation productivity and market tightness work in opposite directions (see also Mortensen and Pissarides 2001).

Taking into account the budget constraint of the unemployment insurance, the ambiguous effect is resolved under certain conditions.

For the budget constraint, equation (18), we obtain after totally differentiating

$$
d t=\frac{b+t+\lambda G\left(\epsilon_{d}\right) T}{1-u} d u-\lambda G\left(\epsilon_{d}\right) d T-\lambda g\left(\epsilon_{d}\right) T d \epsilon_{d}
$$

Using the budget constraint, equation (18), to eliminate $t$ leads to

$$
d t=\frac{b}{(1-u)^{2}} d u-\lambda G\left(\epsilon_{d}\right) d T-\lambda g\left(\epsilon_{d}\right) T d \epsilon_{d}
$$

Equation (24) states that employment taxes $t$ decrease with decreasing unemployment. With increasing dismissal taxes $T$, they decrease because of the direct financing effect of substituting $t$ by $T$. A decrease in the reservation productivity decreases the tax base of the dismissal taxes and therefore employment taxes $t$ have to be increased.

The change of unemployment $d u$ is obtained by totally differentiating equation (17), which yields

$$
d u=\frac{\lambda g\left(\epsilon_{d}\right) \theta q(\theta)}{\left(\lambda G\left(\epsilon_{d}\right)+\theta q(\theta)\right)^{2}} d \epsilon_{d}-\frac{\lambda G\left(\epsilon_{d}\right) q(\theta)(1-\eta(\theta))}{\left(\lambda G\left(\epsilon_{d}\right)+\theta q(\theta)\right)^{2}} d \theta
$$

with $0<\eta(\theta)=-\frac{\theta q^{\prime}(\theta)}{q(\theta)}<1$ being the elasticity of $q(\theta)$. Unemployment decreases with increasing market tightness since more jobs are created and increases with reservation productivity since more jobs are destroyed.

Inserting equation (25) into (24) yields

$$
d t=b\left[\frac{\lambda g\left(\epsilon_{d}\right)}{\theta q(\theta)} d \epsilon_{d}-\frac{\lambda G\left(\epsilon_{d}\right) q(\theta)(1-\eta(\theta))}{(\theta q(\theta))^{2}} d \theta\right]-\lambda G\left(\epsilon_{d}\right) d T-\lambda g\left(\epsilon_{d}\right) T d \epsilon_{d} .
$$

\footnotetext{
${ }^{5}$ See for example Bertola (1990, 1999), Garibaldi (1998) and Mortensen, Pissarides (2001).
} 
The term in brackets of equation (26) is the decomposed effect of the change in unemployment. There are now two channels influencing $t$ through the reservation productivity $\epsilon_{d}$. Next to the tax base effect described above, a rise in reservation productivity increases employment taxes $t$ through the unemployment channel. Thereby, as long as the system is not fully financed by dismissal taxes $\left(t>0 \text { and respectively } \frac{b}{\theta q(\theta)}>T\right)^{6}$, the effect via the unemployment rate dominates the tax base effect.

Inserting the change of employment taxes $t$ into the totally differentiated JD and JC, formally inserting equation (26) into equation (19) - while there is no effect on equation (20) -, we derive the effects of a change of dismissal taxes $T$ on reservation productivity and market tightness, taking into account the budget constraint of the unemployment insurance. The change in market tightness equals (for calculations see Appendix D)

$$
d \theta=\frac{1}{Q}(1-\beta)\left(b \frac{\lambda g\left(\epsilon_{d}\right)}{\theta q(\theta)}-\lambda g\left(\epsilon_{d}\right) T\right) d T
$$

where

$$
Q=D+\left(b \frac{\lambda g\left(\epsilon_{d}\right)}{\theta q(\theta)}-\lambda g\left(\epsilon_{d}\right) T\right) \frac{c q^{\prime}(\theta)}{q(\theta)^{2}}-b \frac{\lambda G\left(\epsilon_{d}\right) q(\theta)(1-\eta(\theta))}{[\theta q(\theta)]^{2}} \frac{(1-\beta)}{r+\lambda}
$$

The sign of $\mathrm{Q}$ is determined by the combination of the policy parameters $t$ and $T$. As long as an increase of employment taxes $t$ creates a budget surplus for given dismissal taxes $T$, the sign is positive (roughly spoken, as long as the equilibrium is on the increasing part of the Laffer curve - for a proof see Appendix E).

Equation (27) states that as long as the unemployment insurance is not fully financed by dismissal taxes and $Q>0$, an increase of dismissal taxes leads to an increase of market tightness. Therefore, this kind of employment protection has no adverse effects on job creation. Considering the job destruction decision of the firm, equation (27), together with equation (20) yields

$$
d \epsilon_{d}=-\frac{1}{Q}(r+\lambda)\left(Q-\frac{c}{q(\theta)^{2}} q^{\prime}(\theta)\left(b \frac{\lambda g\left(\epsilon_{d}\right)}{\theta q(\theta)}-\lambda g\left(\epsilon_{d}\right) T\right)\right) d T .
$$

The reservation productivity decreases unambiguously as long as $Q>0$ and the system is not fully financed by dismissal taxes. This must be the case since the JC still holds. As dismissal taxes and market tightness increase, reservation productivity must fall.

Summing up, as long as the unemployment insurance is not fully financed by dismissal taxes and an increase in $t$ leads to a budget surplus $(Q>0)$, a rise in the dismissal tax will increase market tightness, while the reservation productivity will decrease. Therefore, unemployment unambiguously falls, in contrast to the results of the effect of pure firing costs (see also equation (25)).

\footnotetext{
${ }^{6}$ Note that $\frac{b}{\theta q(\theta)}$ equals unemployment benefits $b$ times the mean duration of unemployment $\frac{1}{\theta q(\theta)}$.
} 
This can be explained by the negative externality that results when financing unemployment benefits by employment taxes $t$. Dismissals take place if they are efficient from the point of view of the firm-worker pair. Increasing dismissal taxes $T$ makes the two parties take into account the total effect of their decision. By doing so, the total burden to finance the unemployment insurance given by employment taxes $t$ and dismissal taxes $T$ decreases ${ }^{7}$. The value of new jobs and therefore market tightness increase.

As equations (21) and (26) show, the increase in firm value can be decomposed into three effects. An increase of $T$ leads to the direct financing effect of substituting employment taxes $t$ by dismissal taxes $T$. This nullifies the negative effect of the dismissal taxes on the job value discussed above. On the one hand, as can be seen in equation (26), $t$ and $T$ cannot be substituted fully to achieve the direct financing effect, because less dismissals lead to the tax base effect. This makes it necessary to increase the employment taxes $t$ to have a balanced budget. On the other hand, as can also be seen in equation (26), the decrease of dismissals lowers the financial requirements of the unemployment insurance and $t$ can be decreased. The latter effect dominates the first effect as long as the system is not fully financed by dismissal taxes. So in total firms face less taxes. This is due to the internalization of the externalities mentioned. The argument holds as long as an increase in employment taxes $t$ leads to an increase in the unemployment insurance's revenues $(Q>0)^{8}$.

The increase of firm value makes more firms enter the market, market tightness $\theta$ increases until it balances firm value and search costs. Additionally, this increase also reduces unemployment and therefore reinforces the decrease in employment taxes.

\section{Conclusion}

The main conclusions of the paper can be summarized as follows. It can be shown that augmenting dismissal taxes increases market tightness, when the budget constraint of unemployment insurance is taken into account. Reservation productivity still falls. Therefore, the unemployment rate unambiguously decreases. This holds as long as unemployment insurance is not fully financed by dismissal taxes and an increase in employment taxes leads to a surplus in the budget of the unemployment insurance for a given level of dismissal taxes.

Neglecting the budget constraint effect, the model describes the standard effects that occur in matching models when introducing dismissal taxes. The reservation productivity decreases, which leads to less dismissals on the one hand. But market tightness decreases as well, which leads to the creation of fewer vacancies on the other hand. The effect on the unemployment rate is ambiguous.

\footnotetext{
${ }^{7}$ The two-tier wage contract guarantees that firms and workers share these costs according to their bargaining power even if the fraction of $t$ and $T$ for financing the unemployment insurance are changed.

${ }^{8}$ If the system was located on the downward sloping part of the Laffer-curve $(Q<0)$, the changes of $t$ mentioned above would be reversed and market tightness would decrease. The effect on unemployment would then be ambiguous.
} 
The difference originates from the budget constraint of unemployment insurance. An increase in market tightness results because the externalities arising from the use of employment taxes are resolved by the use of dismissal taxes. The effect that the financial requirements of the unemployment insurance decrease due to fewer dismissals dominates the tax base effect. Therefore, employment taxes can be reduced more than the equivalent increase of dismissal taxes. The firm's burden to finance unemployment insurance decreases, which augments the value of new jobs and makes it more attractive for firms to supply vacancies.

Weakening the assumption that there exists a two-tier wage contract and assuming that workers directly renegotiate wages, the results would be less clear cut. In this case, the influence of dismissal taxes on unemployment highly depends on the bargaining power of workers. As workers cannot be forced to accept a lower wage at the beginning of the employment relationship, firms have to fully bear dismissal taxes, while employment taxes are effectively shared between firms and workers. For no bargaining power of workers the above presented results still hold. For positive bargaining power of workers, the positive effect on market tightness is reduced and may even be reversed.

\section{Mathematical Appendix}

\section{A Wage Bargaining}

Maximizing equation (8) with respect to $w(\epsilon)$ yields the following first order condition:

$$
\beta(W(\epsilon)-U)^{\beta-1}(J(\epsilon)+T)^{1-\beta} \frac{\partial W(\epsilon)}{\partial w(\epsilon)}=-(1-\beta)(W(\epsilon)-U)^{\beta}(J(\epsilon)+T)^{-\beta} \frac{\partial J(\epsilon)}{\partial w(\epsilon)}
$$

As $\frac{\partial W(\epsilon)}{\partial w(\epsilon)}=-\frac{\partial J(\epsilon)}{\partial w(\epsilon)}=\frac{1}{r+\lambda}$, this translates into the sharing rule, equation (10).

Inserting equations (1) and (6) for $J(\epsilon)$ and $W(\epsilon)$, we obtain

$$
\begin{aligned}
& (1-\beta)\left(w(\epsilon)+\lambda\left(\int_{\epsilon_{d}}^{\epsilon_{u}} W(x) d G(x)+G\left(\epsilon_{d}\right) U\right)-(r+\lambda) U\right) \\
= & \beta\left(\epsilon-w(\epsilon)-t+\lambda\left(\int_{\epsilon_{d}}^{\epsilon_{u}} J(x) d G(x)+G\left(\epsilon_{d}\right)(-T)\right)+(r+\lambda) T\right) .
\end{aligned}
$$

Solving for $w(\epsilon)$ and using the sharing rule, equation (10), to eliminate the integrals yields

$$
w(\epsilon)=\beta(\epsilon-t+r T)+(1-\beta) r U=r U+\beta(\epsilon-t+r T-r U) .
$$

If worker and firm bargain for the first time, the fall back position of the firm is $V=0$. When using equation (4), equation (11) can be reweitten to

$$
\left(W^{0}-U\right)=\frac{\beta}{1-\beta} \frac{c}{q(\theta)} .
$$


Substituting equation (31) into the life time utility of an unemployed, equation (5) yields

$$
r U=b+\theta q(\theta) \frac{\beta}{1-\beta} \frac{c}{q(\theta)}=b+\frac{\beta}{1-\beta} \theta c .
$$

Inserting equation (32) into (30) leads to the wage equation (12). Analogously the wage equation for the initial wage, equation (13), can be derived, using equations (2), (7) and (9), and maximizing over $w^{0}$.

\section{B Job Destruction and Job Creation Condition}

To calculate the reservation productivity and market tightness, the values of continuing and

new jobs have to be calculated. Substituting the wage equation (12) into equation (1) yields

$$
(r+\lambda) J(\epsilon)=(1-\beta)(\epsilon-t-b)-\beta(c \theta+r T)+\lambda\left(\int_{\epsilon_{d}}^{\epsilon_{u}} J(x) d G(x)-G\left(\epsilon_{d}\right) T\right) .
$$

Therefore, the firm value can be calculated from

$$
(r+\lambda)\left(J(\epsilon)-J\left(\epsilon_{d}\right)\right)=(1-\beta)\left(\epsilon-\epsilon_{d}\right)
$$

as

$$
J(\epsilon)=\frac{(1-\beta)\left(\epsilon-\epsilon_{d}\right)}{r+\lambda}-T .
$$

Using equation (34) and (14) to evaluate equation (33) for the reservation productivity $\epsilon_{d}$ yields

$(r+\lambda) J\left(\epsilon_{d}\right)=-(r+\lambda) T=(1-\beta)\left(\epsilon_{d}-t-b\right)-\beta(c \theta+r T)+\frac{\lambda(1-\beta)}{r+\lambda} \int_{\epsilon_{d}}^{\epsilon_{u}}\left(z-\epsilon_{d}\right) d G(z)-\lambda T$

which can be transformed to equation (15).

To calculate the present discounted value of a newly created job, we combine equation (2), (13) and (14)

$$
(r+\lambda)\left(J^{0}+T\right)=(1-\beta)\left(\epsilon_{u}-\epsilon_{d}\right)+\beta(r+\lambda) T
$$

which finally in combination with equation (4) yields equation (16). 


\section{Basic Effects of Changes in Employment Taxes and Dismissal Taxes}

Rearranging equations (19) and (20), putting the political parameters $d t$ and $d T$ on the rhs, while putting the endogenous variables $d \epsilon_{d}$ and $d \theta$ on the lhs the equations can be rewritten as

$$
\underbrace{\left(\begin{array}{cc}
-\frac{1}{r+\lambda}\left(r+\lambda G\left(\epsilon_{d}\right)\right) & \frac{\beta c}{1-\beta} \\
-\frac{(1-\beta)}{r+\lambda} & \frac{c q^{\prime}(\theta)}{q(\theta)^{2}}
\end{array}\right)}_{=B}\left(\begin{array}{c}
d \epsilon_{d} \\
d \theta
\end{array}\right)=\left(\begin{array}{cc}
-1 & r \\
0 & 1-\beta
\end{array}\right)\left(\begin{array}{c}
d t \\
d T
\end{array}\right) .
$$

With $D=\operatorname{det}(B)$, rearranging $(35)$ yields

$$
\left(\begin{array}{c}
d \epsilon_{d} \\
d \theta
\end{array}\right)=\frac{1}{D}\left(\begin{array}{cc}
\frac{c q^{\prime}(\theta)}{q(\theta)^{2}} & -\frac{\beta c}{1-\beta} \\
\frac{(1-\beta)}{r+\lambda} & -\frac{1}{r+\lambda}\left(r+\lambda G\left(\epsilon_{d}\right)\right)
\end{array}\right)\left(\begin{array}{cc}
-1 & r \\
0 & 1-\beta
\end{array}\right)\left(\begin{array}{c}
d t \\
d T
\end{array}\right)
$$

leading to equations (22) and (23).

\section{Total Effects of Changes in Employment and Dis- missal Taxes}

Inserting the change of the employment taxes $t$ caused by a change of dismissal taxes $T$, equation (26), into equation (35) yields after rearranging

$$
\underbrace{\left(\begin{array}{cc}
-\frac{1}{r+\lambda}\left(r+\lambda G\left(\epsilon_{d}\right)\right)+\left(b \frac{\lambda g\left(\epsilon_{d}\right)}{\theta q(\theta)}-\lambda g\left(\epsilon_{d}\right) T\right) & \frac{\beta c}{1-\beta}-b \frac{\lambda G\left(\epsilon_{d}\right) q(\theta)(1-\eta(\theta))}{[\theta q(\theta)]^{2}} \\
\frac{c q^{\prime}(\theta)}{q(\theta)^{2}}
\end{array}\right)}_{C}\left(\begin{array}{c}
d \epsilon_{d} \\
d \theta
\end{array}\right)=\left(\begin{array}{c}
r+\lambda G\left(\epsilon_{d}\right) \\
1-\beta
\end{array}\right) d T
$$

where $Q=\operatorname{det}(C)$ equals

$$
\begin{aligned}
Q= & -\left[\frac{1}{r+\lambda}\left(r+\lambda G\left(\epsilon_{d}\right)\right)-\left(b \frac{\lambda g\left(\epsilon_{d}\right)}{\theta q(\theta)}-\lambda g\left(\epsilon_{d}\right) T\right)\right] \frac{c q^{\prime}(\theta)}{q(\theta)^{2}} \\
& -\left[-\frac{\beta c}{1-\beta}+b \frac{\lambda G\left(\epsilon_{d}\right) q(\theta)(1-\eta(\theta))}{[\theta q(\theta)]^{2}}\right] \frac{(1-\beta)}{r+\lambda} .
\end{aligned}
$$

Inverting $C$ and solving equation (36) for the vector $\left(\begin{array}{c}d \epsilon_{d} \\ d \theta\end{array}\right)$ yields

$$
\left(\begin{array}{c}
d \epsilon_{d} \\
d \theta
\end{array}\right)=\frac{1}{Q}\left(\begin{array}{cc}
\frac{c q^{\prime}(\theta)}{q(\theta)^{2}} & -\frac{\beta c}{1-\beta}+b \frac{\lambda G\left(\epsilon_{d}\right) q(\theta)(1-\eta(\theta))}{[\theta q(\theta)]^{2}} \\
\frac{(1-\beta)}{r+\lambda} & -\frac{1}{r+\lambda}\left(r+\lambda G\left(\epsilon_{d}\right)\right)+\left(b \frac{\lambda g\left(\epsilon_{d}\right)}{\theta q(\theta)}-\lambda g\left(\epsilon_{d}\right) T\right.
\end{array}\right)\left(\begin{array}{c}
r+\lambda G\left(\epsilon_{d}\right) \\
1-\beta
\end{array}\right) d T
$$


which equals

$$
\left(\begin{array}{c}
d \epsilon_{d} \\
d \theta
\end{array}\right)=\frac{1}{Q}\left(\begin{array}{c}
\frac{c q^{\prime}(\theta)}{q(\theta)^{2}}\left(r+\lambda G\left(\epsilon_{d}\right)\right)-\frac{\beta c}{1-\beta}+b \frac{\lambda G\left(\epsilon_{d}\right) q(\theta)(1-\eta(\theta))}{[\theta q(\theta)]^{2}} \\
(1-\beta)\left(b \frac{\lambda g\left(\epsilon_{d}\right)}{\theta q(\theta)}-\lambda g\left(\epsilon_{d}\right) T\right)^{2}
\end{array}\right) d T
$$

\section{E Sign of Determinant $Q$}

It is possible to demonstrate that $Q>0$ as long as an increase in employment taxes leads to an increase of the surplus in the unemployment insurance. According to the budget constraint, equation (18), the surplus of unemployment insurance $A$ is defined as

$$
A=(1-u)\left(t+\lambda G\left(\epsilon_{d}\right) T\right)-b u .
$$

Totally differentiating $A$ with respect to employment taxes $t$ yields

$$
\frac{d A}{d t}=(1-u)-\left(t+\lambda G\left(\epsilon_{d}\right) T+b\right) \frac{d u}{d t}+(1-u) \lambda g\left(\epsilon_{d}\right) T \frac{d \epsilon_{d}}{d t} .
$$

Substituting the employment taxes $t$ according to equation (38) yields

$$
\frac{d A}{d t}=(1-u)-\left(\frac{A+b}{1-u}\right) \frac{d u}{d t}+(1-u) \lambda g\left(\epsilon_{d}\right) T \frac{d \epsilon_{d}}{d t}
$$

With $(1-u)=\frac{\theta q(\theta)}{\lambda G\left(\epsilon_{d}\right)+\theta q(\theta)}$ and partly inserting equation (25) for $\frac{d u}{d t}$ the last expression can be rewritten as

$$
\frac{d A}{d t}=(1-u)\left[1+\lambda g\left(\epsilon_{d}\right)\left(T-\frac{b}{\theta q(\theta)}\right) \frac{d \epsilon_{d}}{d t}+\frac{\lambda G\left(\epsilon_{d}\right) q(\theta)(1-\eta(\theta)) b}{(\theta q \theta)^{2}} \frac{d \theta}{d t}\right]-\frac{A}{1-u} \frac{d u}{d t} .
$$

The corresponding changes in the reservation productivity $\epsilon_{d}$ and market tightness $\theta$ when changing the employment taxes $t$ are given by equation (22) and (23) as $\frac{d \epsilon_{d}}{d t}=-\frac{1}{D} \frac{c q^{\prime}(\theta)}{q(\theta)^{2}}$ and $\frac{d \theta}{d t}=-\frac{1}{D} \frac{1-\beta}{r+\lambda}$. Therefore,

$$
\begin{aligned}
\frac{d A}{d t} & =\frac{1-u}{D}\left[D+\lambda g\left(\epsilon_{d}\right)\left(\frac{b}{\theta q(\theta)}-T\right) \frac{c q^{\prime}(\theta)}{q(\theta)^{2}}-b \frac{\lambda G\left(\epsilon_{d}\right) q(\theta)(1-\eta(\theta))}{(\theta q(\theta))^{2}} \frac{1-\beta}{r+\lambda}\right]-\frac{A}{1-u} \frac{d u}{d t} \\
& =\frac{1-u}{D} Q-\frac{A}{1-u} \frac{d u}{d t} .
\end{aligned}
$$

If, as postulated in the model, the budget of the unemployment insurance is balanced in steady state $(A=0)$, the sign of $Q$ equals the sign of $\frac{d A}{d t}$. Therefore, as long as an increase in employment taxes $t$ leads to a surplus in unemployment insurance in steady state, the sign of $Q$ is positive. 


\section{References}

Anderson, P. and Meyer, B. (2000). "The Effects of the Unemployment Insurance Payroll Tax on Wages, Employment, Claims and Denials", Journal of Public Economics 78, 81-106.

Belot, M., Boone, J., and van Ours, J. (2002). "Welfare Effects of Employment Protection", CEPR Discussion Paper, 3396.

Bertola, G. (1990). "Job Security, Employment and Wages", European Economic Review $34,851-886$.

Bertola, G. (1999). "Microeconomic Perspectives on Aggregate Labor Markets", in O.Ashenfelter and D.Card (edt.), Handbook of Labor Economics, Volume 3C, Elsevier, Amsterdam, 29853028.

Blanchard, O. and Tirole, J. (2004). "The Optimal Design of Unemployment Insurance and Employment Protection. A First Pass", NBER Working Paper 10443.

Bovenberg, A. (2003). "Tax Policy and Labor Market Performance", CESifo Working Paper 1035 .

Garibaldi, P. (1998). "Job Flow Dynamics and Firing Restrictions", European Economic Review 42, 245-275.

German Council of Economic Experts (2003). "Staatsfinanzen konsolidieren - Steuersystem reformieren", Elsevier Group, Reutlingen.

Millard, S. P. and Mortensen, D. T. (1997). "The Unemployment and Welfare Effects of Labour Market Policy: A Comparison of the USA and the UK", in Snower, D. J. and de la Dehesa, G. (edt.), Unemployment Policy. Government Options for the Labour Market, Cambridge University Press, Cambridge.

Mortensen, D. T. and Pissarides, C. (1994). "Job Creation and Job Destruction in the Theory of Unemployment", Review of Economic Studies 61, 397-415.

Mortensen, D. T. and Pissarides, C. (1999). "New Developments in Models of Search in the Labor Market", in O.Ashenfelter and D.Card (edt.), Handbook of Labor Economics, Volume 3B, Elsevier, Amsterdam, 2567-2627.

Mortensen, D. T. and Pissarides, C. (2001). "Taxes, Subsidies, and Equilibrium Labour Market Outcomes", CEPR Discussion Paper, 2989. 
OECD (2004). "Employment Outlook", Paris.

Pissarides, C. (2000). "Equilibrium Unemployment Theory", Cambridge USA: MIT Press.

Rocheteau, G. (1999a). "Balanced-budget Rules and Indeterminacy of the Equilibrium Unemployment Rate", Oxford Economic Papers 51, 399-409.

Rocheteau, G. (1999b). "Can an Unemployment Insurance System Generate Multiple Natural Rates?", International Tax and Public Finance 6, 379-387. 